\title{
PENGEMBANGAN PENYUSUNAN INSTRUMEN FOUR-TIER DIAGNOSTIC TEST UNTUK MENGUNGKAP MISKONSEPSI MATERI SISTEM EKSKRESI DI SMA NEGERI 1 MAYONG JEPARA
}

\author{
Nurul Wilantika $^{1}$, Nur Khoiri ${ }^{2}$, Saifullah Hidayat ${ }^{3}$ \\ 1,2,3 Jurusan Pendidikan Biologi UIN Walisongoi Semarang
}

\begin{abstract}
This study aims to develop and describe feasibility a Four-tier diagnostic test instrument to figure out students' misconceptions in the material of the Excretion System.This study aims to develop a Four-tier diagnostic test instrument to figure out students' misconceptions in the material of the Excretion System. The type of this study is $R \& D$ (Research and Development) from Sugiyono (2017) with 10 stages. Those 10 stages are identification of potential and problems, data collection, product design, product validation, design revisions, product trials, product revisions, usage trials, product revisions and mass production. The trial subjects were students of class XII MIPA 3 (Test instrument), class XI MIPA 2 (product trial) and class XI MIPA 1 and class XI MIPA 4 (trial use) SMA Negeri 1 Mayong Jepara. This study used observation, documentation, questionnaire, interview and test as research method. First finding, the Four-Tier Diagnostic Test consists of four levels; the question, the level of answer confidence, reason and level of reasoning confidence. The instruments produced include grids, work instructions, test questions, answer keys, answer sheets, scoring guidelines and results interpretation guidelines. Second finding, the results showed that the Four-tier diagnostic test instrument was feasible to be used to reveal student misconceptions. Validity testing by 9 validators shows that the instrument developed is valid. Test validity shows 7 valid category questions, 16 invalid category questions. Test reliability developed by 0.699 means that the problem is reliable. Characteristics of the questions developed were (1) Difficulty level (2 difficult questions, 10 moderate questions, 8 easy questions and 3 very easy questions), (2) Different Power (2 good questions, 17 enough questions and 4 bad questions), and ( 3) Foolers can function properly. There are 41 misconceptions from 13 sub-topics developed.
\end{abstract}

Keywords: Four-Tier Diagnostic Test, Misconception, Excretion System

UIN Walisongo Semarang

Email: nurulwilantika612@gmail.com
C2018 Universitas Islam Negeri Walisongo 200

ISSN: 2088-7868, e-ISSN 2502-5708 


\begin{abstract}
Abstrak
Penelitian ini bertujuan untuk mengembangkan dan mendeskripsikan kelayakan instrumen Four-tier diagnostic test untuk mengungkap miskonsepsi siswa pada materi Sistem Ekskresi. Jenis penelitian ini adalah $R \& D$ (Research and Development) dari Sugiyono (2017) dengan 10 tahap. Tahap-tahap tersebut adalah identifikasi potensi dan masalah, pengumpulan data, desain produk, validasi produk, revisi desain, uji coba produk, revisi produk, uji coba pemakaian, revisi produk dan produksi massal. Subjek uji coba adalah siswa kelas XII MIPA 3 (Uji instrumen), kelas XI MIPA 2 (uji coba produk) serta kelas XI MIPA 1 dan kelas XI MIPA 4 (uji coba pemakaian) SMA Negeri 1 Mayong Jepara. Metode yang digunakan dalam penelitian ini adalah observasi, dokumentasi, angket, wawancara dan tes. Temuan pertama, Four-Tier Diagnostic Test terdiri atas empat tingkatan, yaitu pertanyaan, tingkat keyakinan jawaban, alasan dan tingkat keyakinan alasan. instrumen yang dihasilkan meliputi kisi-kisi, petunjuk pengerjaan, soal tes, kunci jawaban, lembar jawab, pedoman penskoran dan pedoman interpretasi hasil. Temuan kedua, hasil penelitian menunjukkan bahwa instrumen Four-tier diagnostic test layak digunakan untuk mengungkap miskonsepsi siswa. Pengujian validitas oleh 9 validator menunjukkan instrumen yang dikembangkan valid. Validitas tes menunjukkan 7 soal kategori valid, 16 soal kategori tidak valid. Reliabilitas tes yang dikembangkan sebesar 0,699 yang berarti soal tersebut reliable. Karakteristik soal yang dikembangkan yaitu (1) Tingkat Kesukaran (2 soal sukar, 10 soal sedang, 8 soal mudah dan 3 soal sangat mudah), (2) Daya Beda (2 soal baik, 17 soal cukup dan 4 soal jelek), dan (3) Pengecoh dapat berfungsi dengan baik. Terdapat 41 temuan miskonsepi dari 13 sub pokok bahasan yang dikembangkan.
\end{abstract}

Kata kunci: Four-Tier Diagnostic Test, Miskonsepsi, Sistem Ekskresi 


\section{PENDAHULUAN}

Belajar pada dasarnya merupakan proses usaha aktif seseorang untuk memperoleh sesuatu sehingga terbentuk perilaku baru menuju arah yang lebih baik. (Septiana, 2014: 2). Namun kenyataannya, siswa seringkali tidak mampu mencapai tujuan belajarnya atau tidak memperoleh perubahan tingkah laku sebagaimana yang diharapkan.Hal ini menunjukkan bahwa siswa mengalami kesulitan belajar dalam mencapai hasil belajar terutama kurangnya pemahaman siswa pada konsep (Septiana, 2014: 2).Pemahaman konsep merupakan dasar dari pemahaman prinsip-prinsip teori, artinya agar dapat memahami suatu prinsip dan teori harus dikuasai terlebih dahulu konsep-konsep yang menyusun prinsip tersebut. (Fitrianingrum,dkk, 2017: 88). Sumber kekeliruan dalam memahami konsep dapat terjadi karena penafsiran siswa yang salah atau yang disebut miskonsepsi (Susanti,dkk, 2014: 1). Miskonsepsi dapat juga diartikan konsep yang dimiliki siswa tidak sesuai dengan konsep ilmuwan.Penyebab miskonsepsi pada siswa dapat disebabkan oleh beberapa hal seperti kesalahan dari siswa sendiri, kesalahan dari guru ketika menjelaskan pelajaran, kesalahan dari buku teks yang digunakan, kesalahan konteks dan kesalahan dari metode mengajar yang digunakan oleh guru saat pembelajaran (Suparno, 2005:4).Cara mengatasi miskonsepsi yang terjadi di kalangan siswa adalah dengan mendiagnosa miskonsepsi-miskonsepsi yang di alami siswa menggunakan tes diagnostik.

Tes diagnostik telah banyak dikembangkan untuk menganalisis miskonsepsi siswa lebih dalam.Tes diagnostik dapat berupa tes berbentuk soal pilihan ganda maupun uraian.Tes diagnostik yang baik dapat memberikan gambaran akurat mengenai miskonsepsi yang dialami oleh siswa berdasarkan informasi kesalahan yang dibuatnya. Pertanyaan diagnostik yang baik tidak hanya menunjukkan bahwa siswa tidak memahami bagian materi tertentu, akan tetapi juga dapat menunjukkan bagaimana siswa berpikir dalam menjawab pertanyaan yang diberikan meskipun jawaban mereka tidak benar (Fariyani, 2015: 42). Soal pilihan ganda untuk mendeteksi miskonsepsi siswa telah dikembangkan dari One-Tier menjadi Two-Tier, Three-Tier dan Four-Tier. Four-Tier Diagnostic Test merupakan pengembangan dari Three-Tier Diagnostic Test yang terdiri atas soal pilihan ganda dengan 3 pengecoh dan 1 kunci jawaban yang harus 
dipilih siswa, tingkat keyakinan siswa dalam memilih jawaban, alasan siswa menjawab pertanyaan dengan 3 alasan siswa menjawab pertanyaan dan 1 alasan terbuka serta tingkat keyakinan siswa dalam memilih alasan. Tingkat keyakinan dalam memilih jawaban maupun alasan terbagi atas skala satu sampai enam. Skala satu dipilih jika siswa menebak, skala dua jika siswa sangat tidak yakin, skala tiga jika siswa tidak yakin, skala empat jika siswa yakin, skala lima jika siswa sangat yakin dan skala enam jika siswa amat sangat yakin.

Menurut Depdiknas (2007: 6), langkah-langkah penyusunan instrumen Four-Tier Diagnostic Test adalah (1) Mengidentifikasi Kompetensi dasar yang belum tercapai ketuntasannya, (2) Menentukan kemungkinan sumber masalah, (3) Menentukan bentuk dan jumlah soal yang sesuai, (4) Menyusun kisi-kisi soal, (5) Menulis soal, (6) Mereview soal dan (7) Menyusun kriteria penilaian.

Berdasarkan hasil wawancara dengan siswa dan guru biologi SMA Pondok Modern Selamat Kendal, MA NU Nurul Huda Mangkang Semarang, MA Shofa Marwah, SMA Negeri 1 Pecangaan Jepara dan SMA Negeri 1 Mayong Jepara, materi sistem ekskresi merupakan salah satu materi yang rawan miskonsepsi. Pada materi ini siswa harus memahami konsep sistem ekskresi dengan berbagai proses dan banyak bahasa ilmiah. Oleh karena itu, peneliti bermaksud untuk mengungkap miskonsepsi siswa pada materi sistem ekskresi menggunakan instrument Four-Tier Diagnostic Test. Tujuan dari penelitian ini adalah mengembangkan penyusunan instrumen dan mendeskripsikan kelayakan instrumen Four-Tier Diagnostic Test yang digunakan untuk mengungkap miskonsepsi materi Sistem Ekskresi di SMA Negeri 1 Mayong Jepara tahun pelajaran 2017/2018.

\section{METODE PENELITIAN}

Pengembangan ini menggunakan prosedur Research \& Development (R\&D) yang dikembangkan oleh Sugiyono (2017) yang diadaptasi dari Borg and Gall (2003) yaitu 10 tahapan atau 10 langkah meliputi (1) Potensi dan Masalah, (2) Pengumpulan Data, (3) Desain Produk, (4) Validasi Desain, (5) Revisi Desain, (6) Uji Coba Produk, (7) Revisi Produk, (8) Uji Coba Pemakaian, (9) Revisi Produk, dan (10) Produksi Massal. 
Uji Instrumen dilakukan pada 36 siswa kelas XII MIPA 3, uji coba produk dilakukan pada 15 siswa kelas XI MIPA 2 dan uji coba pemakaian dilakukan pada 68 siswa kelas XI MIPA 1 dan XI MIPA 4 SMA Negeri 1 Mayong Jepara. Metode pengumpulan data terdiri atas metode observasi, wawancara, angket, tes dan dokumentasi. Teknik analisis data yang digunakan meliputi validasi ahli, uji validitas, uji reliabilitas, uji tingkat kesukaran, uji daya beda, analisis fungsi distraktor, interpretasi hasil miskonsepsi dan analisis miskonsepsi.

Pengujian validitas ahli menggunakan validasi isi yang dilakukan oleh 3 dosen ahli, 1 guru biologi dan 5 peer reviewer. Uji validitas menggunakan rumus Korelasi Biserial, uji reliabilitas menggunakan rumus Alpha Cronbach. Tingkat kesukaran menggunakan rumus Indeks Kesukaran. Daya beda menggunakan rumus Determinasi. Analisis fungsi distraktor menggunakan rumus Indeks Pengecoh.Interpretasi hasil dilakukan dengan menggolongkan siswa dalam kelompok paham, tidak paham dan miskonsepsi.interpretasi hasil dapat dilihat pada tabel 1. Tingkat keyakinan tergolong tinggi apabila dipilih dengan skala 4 (yakin), 5 (sangat yakin), dan 6 (amat sangat yakin).Tingkat keyakinan tergolong rendah apabila dipilih dengan skala 1 (menebak), 2 (sangat tidak yakin) dan 3 (tidak yakin). Analisis miskonsepsi siswa menggunakan rumus $\mathrm{CDQ}=(\mathrm{CFC}-\mathrm{CFW}) / \mathrm{S}$ dimana $\mathrm{CDQ}$ (Confidence Discrimation Quotient) merupakan analisis miskonsepsi siswa, CFC merupakan rata-rata tingkat keyakinan siswa yang menjawab benar, CFW merupakan rata-rata tingkat keyakinan siswa yang menjawab salah dan S merupakan standar deviasi tingkat keyakinan. 
Tabel 1. Interpretasi Hasil Four-Tier Diagnostic Test

\begin{tabular}{|c|c|c|c|c|c|}
\hline \multirow[t]{2}{*}{ No } & \multirow[t]{2}{*}{ Kategori } & \multicolumn{4}{|c|}{ Tipe respon } \\
\hline & & Jawaban & $\begin{array}{l}\text { Tingkat } \\
\text { Keyakinan } \\
\text { Jawaban }\end{array}$ & Alasan & $\begin{array}{l}\text { Tingkat } \\
\text { Keyakinan } \\
\text { Alasan }\end{array}$ \\
\hline 1. & Mamahami & Benar & Tinggi & Benar & Tinggi \\
\hline \multirow[t]{8}{*}{2.} & \multirow{8}{*}{$\begin{array}{l}\text { Tidak } \\
\text { memahami }\end{array}$} & Benar & Rendah & Benar & Rendah \\
\hline & & Benar & Tinggi & Benar & Rendah \\
\hline & & Benar & Rendah & Benar & Tinggi \\
\hline & & Benar & Rendah & Salah & Rendah \\
\hline & & Salah & Rendah & Benar & Rendah \\
\hline & & Salah & Rendah & Salah & Rendah \\
\hline & & Benar & Tinggi & Salah & Rendah \\
\hline & & Salah & Rendah & Benar & Tinggi \\
\hline \multirow[t]{7}{*}{3.} & \multirow[t]{7}{*}{ Miskonsepsi } & Benar & Rendah & Salah & Tinggi \\
\hline & & Benar & Tinggi & Salah & Tinggi \\
\hline & & Salah & Tinggi & Benar & Rendah \\
\hline & & Salah & Tinggi & Benar & Tinggi \\
\hline & & Salah & Tinggi & Salah & Rendah \\
\hline & & Salah & Rendah & Salah & Tinggi \\
\hline & & Salah & Tinggi & Salah & Tinggi \\
\hline
\end{tabular}

\section{HASIL DAN PEMBAHASAN}

\section{Pengembangan Four-Tier Diagnostic Test}

Four-Tier Diagnostic Test atau tes diagnostik pilihan ganda empat tingkat yang dikembangkan dalam penelitian ini menghasilkan instrumen tes yang berfungsi untuk mengungkap miskonsepsi siswa pada materi Sistem Ekskresi.Setiap siswa dimungkinkan mengalami miskonsepsi pada materi yang telah mereka pelajari. Menurut Fariyani (2015: 63), sangat penting untuk mengembangkan suatu alat evaluasi yang 
dapat mendeteksi miskonsepsi yang dialami siswa. Hal ini dikarenakan miskonsepsi yang terjadi akan mengakar pada diri siswa dan menghambat siswa dalam mempelajari materi pada jenjang berikutnya. Salah satu alat yang digunakan untuk mendeteksi miskonsepsi adalah tes diagnostik. Bentuk soal tes diagnostik yang dikembangkan dalam penelitian ini adalah soal pilihan ganda yang disertai pilihan alasan siswa memilih jawaban, serta tingkat keyakinan dalam memilih jawaban maupun alasannya selain dapat mendeteksi miskonsepsi, Four-Tier Diagnostic Test juga dapat mendeteksi konsep yang sudah dipahami siswa maupun konsep yang tidak dipahami siswa.

Menurut Depdiknas (2007: 4), karakteristik tes diagnostik adalah (a) tes dirancang untuk mendeteksi kesulitan belajar siswa, (b) tes dikembangkan berdasarkan analisis terhadap sumber-sumber kesalahan atau kesulitan yang mungkin menjadi penyebab masalah siswa, (c) tes menggunakan soal-soal bentuk uraian atau jawaban singkat. Bila menggunakan pilihan ganda harus disertakan alasan mengapa memilih jawaban tertentu sehingga dapat meminimalisir jawaban menebak.Hasil instrument tes yang dikembangkan dapat dilihat pada tabel 2.

Tabel 2. Produk Four-Tier Diagnostic Test

\begin{tabular}{|c|c|c|}
\hline No & Produk yang dikembangkan & Isi \\
\hline 1 & Kisi-kisi Four-Tier Diagnostic Test & $\begin{array}{l}\text { sub pokok bahasan, indikator soal, tingkat } \\
\text { kognitif, nomor soal dan jumlah soal }\end{array}$ \\
\hline 2 & $\begin{array}{l}\text { Petunjuk pengerjaan } \\
\text { Diagnostic Test }\end{array}$ & $\begin{array}{l}\text { petunjuk bagi siswa untuk mengerjakan soal } \\
\text { tes }\end{array}$ \\
\hline 3 & Soal Four-Tier Diagnostic Test & $\begin{array}{l}\text { Nama, kelas, no.Absen, petunjuk pengisian, } \\
\text { soal-soal tes, pilihan jawaban, tingkat } \\
\text { keyakinan jawaban, alasan dan tingkat } \\
\text { keyakinan alasan }\end{array}$ \\
\hline 4 & $\begin{array}{l}\text { Kunci jawaban Four-Tier Diagnostic } \\
\text { Test }\end{array}$ & $\begin{array}{l}\text { No soal, pilihan jawaban dan alasan yang } \\
\text { benar }\end{array}$ \\
\hline 5 & Lembar jawab Four-Tier Diagnostic Test & $\begin{array}{l}\text { kolom nomor soal, kolom pilihan jawaban, } \\
\text { kolom pilihan tingkat keyakinan jawaban, } \\
\text { kolom pilihan alasan dan kolom pilihan } \\
\text { tingkat keyakinan memilih alasan }\end{array}$ \\
\hline 6 & $\begin{array}{l}\text { Pedoman Penskoran } \\
\text { Diagnostic Test }\end{array}$ & $\begin{array}{l}\text { Pedoman dalam memberikan skor dan } \\
\text { menentukan hasil tes }\end{array}$ \\
\hline 7 & $\begin{array}{l}\text { Pedoman Interpretasi Hasil Four-Tier } \\
\text { Diagnostic Test }\end{array}$ & $\begin{array}{l}\text { Pedoman untuk mengklasifikasikan jawaban } \\
\text { yang diberikan siswa }\end{array}$ \\
\hline
\end{tabular}




\section{Validitas Four-Tier Diagnostic Test}

Validitas Four-Tier Diagnostic Test ditentukan melalui validasi oleh ahli.Validasi dilakukan oleh 3 orang ahli, 1 guru biologi dan 5 orang peer reviewer. Validasi dilakukan untuk menentukan apakah instrumen yang digunakan sudah layak dan dapat mengukur apa yang akan diukur, dalam penelitian ini adalah miskonsepsi siswa. Instrumen tes diagnostik awal berjumlah 50 soal yang dikembangkan telah dinyatakan valid oleh validator.Pernyataan ini dibuktikan dengan hasil rata-rata validator ahli sebesar 22,91 yang berarti tiap butir soal tes sangat baik dan Peer Reviewer menyatakan tiap butir soal tes sangat baik dengan rata-rata 23,02 sehingga dapat diujikan ke subjek penelitian.Hal ini menunjukkan bahwa butir soal tes yang dikembangkan telah memiliki kesesuaian dengan isi materi Sistem Ekskresi.

Validitas soal tes dinilai tiap butirnya oleh ahli dan setiap butir soal terdiri atas 24 aspek penilaian yang meliputi segi materi, segi konstruksi, segi bahasa dan tampilan Four-Tier Diagnostic Test. Soal tes yang sudah dinyatakan valid kemudian diujikan terhadap siswa peserta uji instrumen, uji coba produk dan uji coba pemakaian. Penilaian secara detail terhadap butir soal dilakukan agar soal tes yang digunakan benar-benar layak dan dapat mengukur apa yang hendak diukur yaitu miskonsepsi siswa.

Validitas juga hitung melalui hasil uji coba siswa.Soal awal yang diujikan adalah 50 soal kemudian diuji instrumen hasilnya ada 28 soal yang sesuai dengan kualitas butir soal.Setelah itu diuji coba produk, hasilnya ada 23 soal yang sesuai dengan kualitas butir soal.Hasilvaliditas uji coba pemakaian, 7 soal dinyatakan valid dan 16 soal dinyatakan tidak valid.

\section{Reliabilitas Four-Tier Diagnostic Test}

Reliabilitas merupakan tingkat keajegan soal dalam menilai apa yang ingin dinilai. Reliabilitas menyatakan sejauh mana hasil suatu pengukuran dapat dipercaya.Pengujian reliabilitas menggunakan rumus Alpha Cronbach.Analisis reliabilitas menghasilkan nilai reliabilitas sebesar 0,699. Hasil r11 ini lebih besar daripada $\mathrm{r}$ tabel yaitu 0,238. Artinya soal tes yang diberikan reliable. 


\section{Karakteristik Four-Tier Diagnostic Test}

Soal tes yang baik harus valid dan reliable.Selain itu, soal tes harus memiliki tingkat kesukaran dan daya pembeda yang baik. Tingkat kesukaran dan daya pembeda merupakan karakteristik butir soal termasuk Four-Tier Diagnostic Test.

Tingkat kesukaran 23 butir soal terdiri atas 2 butir soal berkategori sukar, 10 butir soal termasuk kategori sedang, 8 butir soal berkategori mudah dan 3 butir soal berkategori sangat mudah. Angka tingkat kesukaran berkisar antara 0,22 sampai dengan 0,94.Tingkat kesukaran sebagian besar butir soal berkategori sedang.Hal tersebut disebabkan soal tes yang baik adalah soal dengan tingkat kesukaran sedang.Tingkat kesukaran sedang diperlukan agar siswa yang kurang pandai tidak terlalu kesulitan dalam mengerjakan soal dan siswa yang pandai tidak terlalu mudah dalam mengerjakan soal. Pemilihan soal dengan tingkat kesukaran sedang juga sesuai dengan penelitian Budiningsih, dkk (2013) dan Fariyani (2015) yang menggunakan soal dengan rata-rata tingkat kesukaran sedang untuk tes diagnostik.

Daya pembeda 23 butir soal terdiri atas 0 butir soal berkategori sangat baik, 2 butir soal berkategori baik, 17 butir soal berkategori cukup dan 4 butir soal berkategori jelek. Angka daya pembeda berkisar antara -0,05 sampai 0,41.Daya pembeda soal FourTier Diagnostic Test yang dikembangkan sebagian besar berkategori cukup yang berarti soal cukup membedakan antara siswa yang pandai dan kurang pandai.Hal ini sesuai dengan pernyataan Nugraeni, dkk (2013) yaitu butir tes yang baik harus dapat membedakan siswa yang benar-benar menguasai materi dengan yang tidak.

\section{Keberfungsian Pengecoh}

Pengecoh setiap butir soal Four-Tier Diagnostic Test materi sistem ekskresi dikategorikan berfungsi dengan baik.Sebuah distraktor dapat dikatakan baik apabila distraktor tersebut mempunyai daya tarik yang besar terhadap peserta tes yang kurang memahami konsep dan minimal dipilih oleh 5\% siswa (Arikunto, 2013).Banyaknya peserta ujian adalah 68 siswa sehingga 5\% dari 68 siswa adalah 4 siswa.Berdasarkan analisis keberfungsian pengecoh pada pilihan jawaban terdapat beberapa nomor yang pengecohnya tidak berfungsi dengan baik diantaranya soal nomor 1, 2, 3, 11, 12, 13, 16, 
17, 18 dan 22.Banyaknya pengecoh yang belum berfungsi karena banyaknya siswa yang mencontek. Pengecoh yang paling berfungsi pada pilihan jawaban terdapat pada soal nomor 10 pengecoh "c" yakni sebanyak 23 siswa yang memilih pengecoh tersebut.Sedangkan analisis keberfungsian pengecoh pada pilihan alasan terdapat beberapa nomor yang pengecohnya tidak berfungsi dengan baik diantaranya soal nomor $1,2,3,4,5,6,10,11,12,17$ dan 19. Pengecoh yang paling berfungsi pada pilihan alasan terdapat pada soal nomor 4 pengecoh "a", 12 pengecoh " $b$ " dan 15 pengecoh "b" yakni sebanyak 36 siswa yang memilih pengecoh tersebut.

\section{Interpretasi Hasil Four-Tier Diagnostic Test}

Data yang diperoleh dari uji pemakaian dianalisis untuk menentukan apakah siswa mengalami miskonsepsi atau tidak.Siswa mengalami miskonsepsi dalam memilih jawaban, alasan maupun keduanya.Miskonsepsi terendah terjadi ketika siswa memilih jawaban dan miskonsepsi tertinggi terjadi ketika siswa memilih jawaban beserta alasannya. Data tersebut mengindikasikan siswa dapat menjawab pertanyaan, akan tetapi tidak mengetahui alasan menjawab pertanyaan tersebut. Pengelompokan miskonsepsi siswa tiap butir soal dapat dilihat pada gambar 1 .

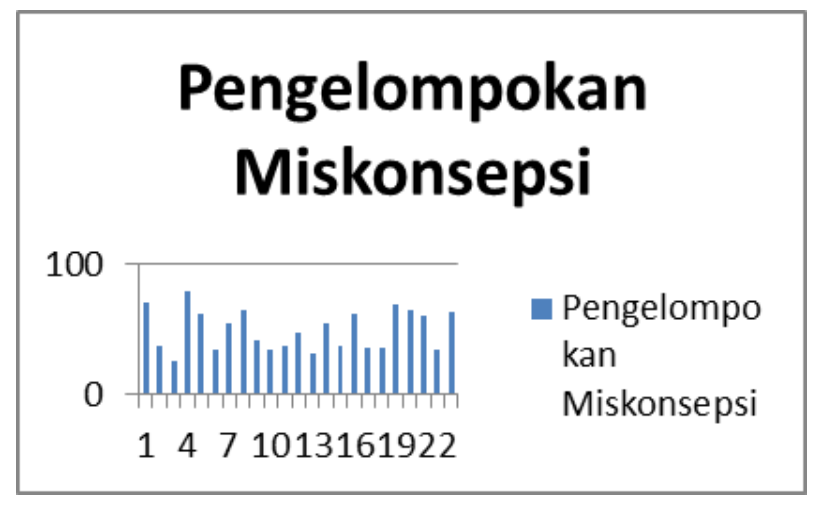

Gambar 1. Grafik pengelompokan miskonsepsi siswa tiap butir soal

Berdasarkan gambar 1, miskonsepsi ditemukan pada setiap butir soal yang diujikan.Miskonsepsi terendah terdapat pada soal nomor 3 yaitu pada indikator mengidentifikasi fungsi bagian ginjal sebesar 25\%. Sedangkan miskonsepsi tertinggi ditemukan pada soal nomor 4 yaitu pada indikator memecahkan masalah tentang 
volume urin makhluk hidup sebesar 79,4\%. Pengelompokan siswa yang tidak memahami konsep disajikan pada gambar 2.

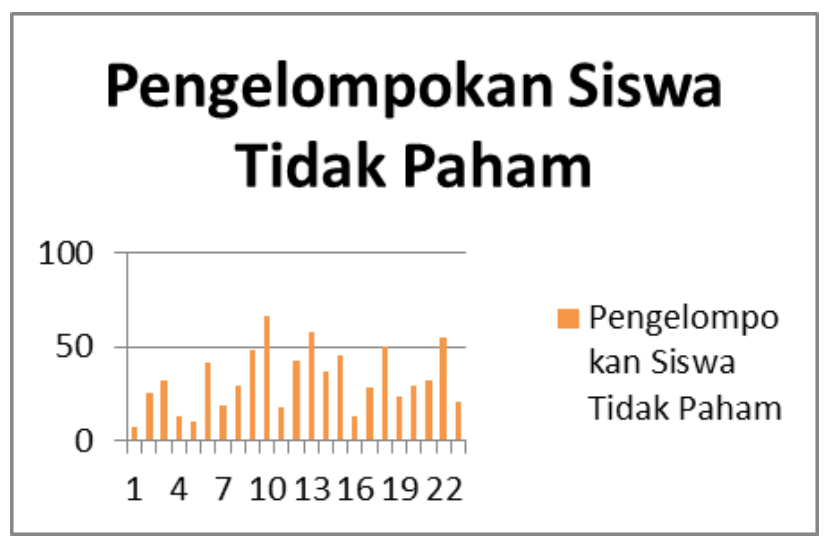

Gambar 2. Grafik pengelompokan siswa yang tidak memahami konsep

Berdasarkan gambar 2, persentase siswa yang tidak memahami konsep terendah ditemukan pada butir soal nomor 1 yaitu pada indikator menjelaskan fungsi sistem ekskresi sebesar 7,4\%. Sedangkan persentase siswa yang tidak memahami konsep tertinggi ditemukan pada butir soal nomor 10 yaitu pada indikator mendiagnosis kelainan yang terjadi pada ginjal sebesar $66,2 \%$. Pengelompokan siswa yang memahami konsep disajikan pada gambar 3.

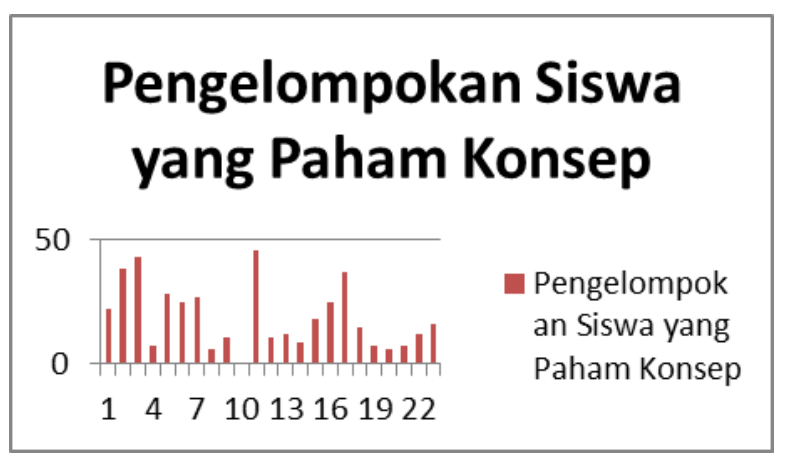

Gambar 3. Grafik pengelompokan siswa yang memahami konsep

Berdasarkan gambar 3, persentase siswa yang memahami konsep terendah ditemukan pada butir soal nomor 10 yaitu pada indikator mendiagnosis kelainan yang terjadi pada ginjal sebesar $0 \%$. Sedangkan persentase siswa yang memahami konsep tertinggi ditemukan pada butir soal nomor 11 yaitu pada indikator mengidentifikasi kelainan yang terjadi pada ginjal sebesar $45,6 \%$. 
Menurut Suwarna (2013) mengkategorikan tingkat miskonsepsi sebagai berikut:

$0 \% \leq \mathrm{P}<30 \% \quad:$ rendah

$30 \% \leq \mathrm{P}<60 \% \quad$ : sedang

$60 \% \leq \mathrm{P}<100 \% \quad$ : tinggi

Terdapat 1 soal yang termasuk miskonsepsi rendah yaitu nomor 3. Terdapat 13 soal yang termasuk miskonsepsi sedang, diantaranya nomor $2,6,7,9,10,11,12,13$, $14,15,17,18$ dan 22 . Terdapat 9 soal yang termasuk miskonsepsi tinggi, diantaranya nomor $1,4,5,8,16,19,20,21$ dan 23.

\section{Temuan Miskonsepsi Siswa}

Data yang digunakan untuk analisis miskonsepsi siswa diperoleh dari hasil tes yang telah dikerjakan siswa pada uji coba pemakaian.Jumlah yang digunakan untuk uji coba pemakaian sebanyak 23 butir soal. Data yang diperoleh tersebut kemudian dianalisis untuk menentukan apakah siswa dapat membedakan apa yang mereka pahami dan apa yang tidak mereka pahami. Analisis dilakukan untuk menentukan nilai CDQ (Confidence Discrimination Quotient). Nilai CDQ negatif mengindikasikan bahwa siswa tidak dapat membedakan apa yang mereka pahami dan apa yang tidak mereka pahami, atau dengan kata lain siswa mengalami miskonsepsi tanpa mereka sadari (Fariyani, 2015: 52).

Tabel 3 Rekapitulasi hasil analisis miskonsepsi siswa

\begin{tabular}{clll}
\hline CDQ & Nomor Soal & \\
\cline { 2 - 4 } & Jawaban & Alasan & Keduanya \\
\hline CDQ $<0$ & $4,10,20,21$ & $1,4,5,7,8,9,10$, & $1,4,5,6,7,8,9,10$, \\
& & $12,13,14,15,16$, & $12,13,14,15,16,18$, \\
& & $23,19,20,21,22$, & $19,20,21,22,23$ \\
& & $\mathbf{1 8}$ & $\mathbf{1 9}$ \\
\hline Jumlah & $\mathbf{4}$ & $2,3,11,17$ \\
\hline \multirow{2}{*}{ C } & $1,2,3,5,6,7$, & $2,3,6,11,17$ & \\
& $8,9,11,12,13$, & & \\
& $14,15,16,17$, & & $\mathbf{4}$ \\
\hline Jumlah & $18,19,22,23$ & & $\mathbf{5}$ \\
\hline
\end{tabular}


Tabel 3 menunjukkan terdapat nilai CDQ negatif pada beberapa nomor soal sehingga dapat disimpulkan bahwa terdapat miskonsepsi yang dialami oleh siswa pada materi sistem ekskresi.Analisis miskonsepsi siswa selengkapnya dapat dilihat pada lampiran. Pengelompokan siswa yang mengalami miskonsepsi dan bukan miskonsepsi disajikan pada gambar 4.

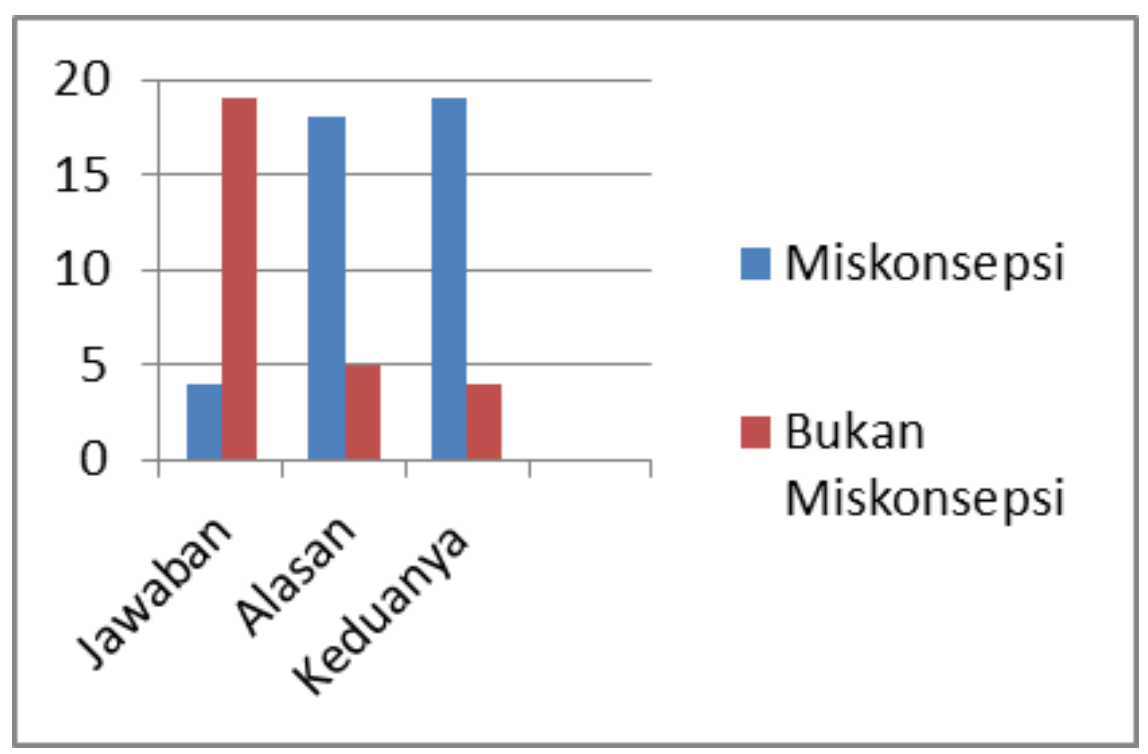

Gambar 4 Grafik pengelompokan siswa yang mengalami miskonsepsi dan bukan miskonsepsi

Tingginya miskonsepsi yang dialami siswa sangat mengkhawatirkan apabila tidak disadari baik oleh guru maupun oleh siswa itu sendiri. Menurut Fariyani (2015: 74), adanya miskonsepsi yang tidak disadari akan melekat pada diri siswa dan terbawa ke jenjang pendidikan berikutnya. Miskonsepsi yang dialami siswa akan mengganggu mereka dalam menerima pengetahuan baru. Konsep yang salah telah tertanam kuat pada diri siswa dan mereka menganggap konsep yang mereka pahami adalah benar. Mereka cenderung akan mengaplikasikan konsep yang mereka yakini sebelumnya dengan konsep yang baru mereka terima. Oleh karena itu, sangat penting untuk segera mengetahui apakah siswa mengalami miskonsepsi dan pada bagian mana siswa mengalami miskonsepsi agar guru dapat segera melakukan tindak lanjut untuk menekan miskonsepsi tersebut. 


\section{SIMPULAN}

Instrumen four-tier diagnostic test yang dihasilkan terdiri atas kisi-kisi soal tes, petunjuk pengerjaan soal, soal tes, kunci jawaban, lembar jawab, pedoman penskoran dan pedoman interpretasi hasil. produk akhir yang dihasilkan berjumlah 23 butir soal terdiri atas 13 sub pokok bahasan dan 22 indikator. Hasil tes dianalisis dan diinterpretasikan untuk menentukan miskonsepsi siswa.

Instrumen four-tier diagnostic test dinyatakan layak digunakan. Validitas instrumen four-tier diagnostic test ditentukan melalui validasi ahli materi, ahli desain penyusunan instrument 1 dan 2, guru biologi dan lima peer reviewer. Validator ahli menyatakan tiap butir soal tes sangat baik sehingga dapat diujikan ke subjek penelitian.validitas juga ditentukan berdasarkan hasil uji coba pemakaian. Hasilnya adalah 7 soal dinyatakan valid. Nilai reliabilitas soal four-tier diagnostic test sebesar 0,699 yang berarti soal tersebut reliable. Tingkat kesukaran soal four-tier diagnostic test terdiri atas 2 butir soal sukar, 10 butir soal sedang, 8 butir soal mudah dan 3 butir soal sangat mudah. Daya pembeda soal four-tier diagnostic test terdiri atas 2 butir soal baik, 17 butir soal cukup dan 4 butir soal jelek. Miskonsepsi ditemukan pada setiap butir soal yang diujikan.Miskonsepsi terendah terdapat pada soal nomor 3 yaitu sebesar $25 \%$. Sedangkan miskonsepsi tertinggi ditemukan pada soal nomor 4 yaitu sebesar 79,4\%. 


\section{DAFTAR PUSTAKA}

Arikunto, Suharsimi. 2012. Dasar-dasar Evaluasi Pendidikan. Jakarta: Bumi Aksara.

Budiningsih, Munardjito dan Asim. 2013. Pengembangan Instrumen Diagnostik ThreeTier untuk Mengidentifikasi Miskonsepsi Listrik Dinamis Siswa Kelas X SMA. Malang: Jurusan Fisika FMIPA UM.

Departemen Pendidikan Nasional. 2007. Tes Diagnostik. Jakarta: Direktorat Jenderal Manajemen Pendidikan Dasar dan Menengah.

Fariyani, Qisthi, dkk. 2015. Pengembangan Four-Tier Diagnostic Test untuk Mengungkap Miskonsepsi Fisika SMA Kelas X. Journal of Innovation Science Education. Vol.4 No.2.Universitas Negeri Semarang.

Fitrianingrum, Aufa Maulida, Sarwi dan Budi Astuti. 2017. Penerapan Instrumen ThreeTier Test untuk Mengidentifikasi Miskonsepsi Siswa SMA pada Materi Keseimbangan Benda Tegar. Jurnal Phenomenon. 7 (2): 88-98.

Nugraeni, D. Jamsuri dan Suwarto. 2013. Penyusunan Tes Diagnostik Materi Listrik Dinamis. Jurnal Pendidikan Fisika. 1(2): 12-15.

Septiana, Dwi. 2014. Identifikasi Miskonsepsi Siswa pada Konsep Archaebacteria dan Eubacteria Menggunakan Two-Tier Multiple Choice.Skripsi. Jakarta: Fakultas Ilmu Tarbiyah dan Keguruan UIN Syarif Hidayatullah Jakarta.

Sugiyono. 2017. Metode Penelitian pendidikan Pendekatan Kuantitatif, Kualitatif dan $R \& D$. Bandung: Alfabeta.

Suparno, Paul. 2005. Miskonsepsi dan Perubahan Konsep dalam Pendidikan Fisika. Jakarta: Grasindo.

Susanti, Dwi, et al. 2014. Penyusunan Instrumen Tes Diagnostik Miskonsepsi Fisika SMA Kelas XI pada Materi Usaha dan Energi.Jurnal Pendidikan Fisika. Vol.2 No.2 Universitas Sebelas Maret.

Suwarno, Iwan Permana. 2013. Analisis Miskonsepsi Siswa SMA Kelas X Mata Pelajaran Fisika Melalui CRI Termodifikasi.Jurnal Metlit. UIN Syarif Hidayatullah Jakarta 